\title{
Conceptual-innovative and energy-resource management on motor transport
}

\author{
Ramazan Khabutdinov ${ }^{1}$, and Arseniy Khabutdinov ${ }^{2}$ \\ ${ }^{1}$ National Transport University, 1, Omelyanovich-Pavlenko, Kiev, 01010, Ukraine \\ ${ }^{2}$ State Enterprise "State Road Transport Research Institute", 57 Peremohy Ave, Kyiv, 03113, Ukraine
}

\begin{abstract}
This paper discusses elements of the theory of conceptual-innovation and energy-resource management based on the system concept of technologically innovative providing of resource synergistic transport integration of a discontinuous terminal infrastructure of a transport system (TS) in accordance with transport demand and the systemic requirement of an innovative increase in the energy-resource quality of transportation services (ERQTS). It has been established that for the system enhancement of ERQTS are actual the development of innovation management theory and the implementation of conceptual improvement strategies for a number of subsystem and system factors: transport resources and technical properties, transport technologies, as well as innovative reproduction functions of the motor transport subsystem (MT) and integrative-equifinal functions of the motor transport system (MTS). The existing theory of service commercial management in MT is based on a simplified non-production and empirically conservative paradigm of knowledge about MT as a sphere of transport services (without product description), therefore it does not fundamentally correspond to the above-mentioned concept of development of MTS and MT. This theory uses computational schemes for virtual transportation and service past costs, so it is non-innovative and technologically degenerate. A theory of conceptual and technologically innovative improvement of ERQTS, as well as the functions of MT and MTS, has been developed. A comprehensive model of the target function of the system-conceptual management of ERQTS is proposed, taking into account the improvement of the MTS and MT functions according to the principle of energy-resource synergy in the transport services life cycle. It takes into account: ways to eliminate the paradoxical fragmentation of types of knowledge about transport operations and processes, improving the properties of a car as a resource- technical means of transport production and reproduction, the essence of transport operations and technologies, as well as dysfunctions of subsystems of MTS.
\end{abstract}

\section{Introduction}

Distinctive features of the motor transport (MT) are as follows: a) a huge variety of transport processes factors (constructive-technical, road, traffic, operation, terminal and technology); b) high levels of trajectorial conflicts and resource expenses in transport operations; c) simplicity, lack of innovation knowledges in theoretical matrices "techno-logos" and "system-logos" in mathematical models of transport analysis. In the early stages of planning the development of technologically innovative transport processes (TP) and motor transport systems (MTS) is necessary to ensure the phasing of implementation of the concept and methodology of their resources- synergistic improvement. This concept is based on a new epistemological paradigm of technological consideration of transport as a sphere of material production and reproduction of transportation services (TS). At the same time MTS is considered as an integrity (on the basis of ensuring its fixihg - transport integration of discontinuous macroeconomics space of countries) of interacting transport and infrastructures elements [1]. The above methodology is based on the conceptual idea of justifying the cumulative effects of two ways of resource saving: a) by transport - using energy- resource quality management methods of transport services in their life-cycle projects taking into account the distinctive features of the motor transport; $b$ ) by infrastructure-based projects of minimization of dysfunctions of the road and terminal infrastructures.

It is accepted that life-cycle of transport services (LCTS) consists of three stages: a) justification of the conceptual quality of technical resources for projects of technologically innovative reproduction of transport services; b) operational production of transport services and consumption of the transport product by the subjects of the macrosystem; c) post operational justification of the conceptual requirements for new technical and technological support for future transport supply. In the resource-synergistic concept, terminal resource saving is ensured by the establishment of a rational logistical time for the implementation of specified chains of terminal operations in projects for the delivery of cargo or passengers lot [2].

* Corresponding author: habut20@gmail.com 
In the road network infrastructure (RNI), resource saving is achieved by minimizing the indices of the trajectory conflicts and of the transport pro-anergic dysfunction of the road sections (TPADRS) [3]. The phenomenon TPADRS occurs when the microsystem "Driver-Car" is functioning under the conditions of the trajectory-conflict street-road network. It is characterized by a significant decrease (by 1.5..4 times) in the degree of use of the constructive-technical potential of the performance and energy efficiency of cars. Any traffic dysfunctions of road sections (low quality of road surfaces, high intensity of automobile traffic, increased trajectory conflicts, irrational traffic light regulation and traffic organization scheme) lead to an increase in the value of the indicator of TPADRS $-\left(K_{t p d} \rightarrow \max\right.$, indicator of transport pro-anergic dysfunction of the road). The logical consequence of this growth is the increase in resources consumption in transport operations $[3,4]$. A necessary condition for the systemic and conceptual improvement of Road network infrastructure (RNI) is the minimization of the indicators of trajectory conflict and of TPADRS $\left(K_{t p d} \rightarrow \min \right)$ of the roads along specified trajectories of automobile traffic.

The existing methodologies of management on Motor transport (MT) and the improvement of Motor transport systems (MTS) at the epistemological level do not correspond to the concept of resource synergistic improvement of MT and MTS. They are based on a very simplified epistemological paradigm: a) considering MT as a sphere of quasi-material transport services (without taking into account the properties of technical resources of transport and RNI elements) with unchanged parameters of cars and transport technologies; b) agglomerate consideration of MTS without regard to its transport and integrative purpose, as well as its structural and functional integrity mechanisms [2,5,6,7,11]. Due to the simplified epistemological paradigm, the existing management methodology has conceptual flaws: a) is: non-conceptual, non-productive, non-technological, nontechnical, non-energy, non-innovative, non-systemic; b) the design scheme of the transpositional operation is used, which describes the virtual movement of the body with cargo (passengers) without taking into account the constructive-technical and resource-technical properties of the new cars, as well as the distinctive features of MT [6]; c) models of past operating expenses for transportation services are considered without taking into account the resource-cost and energy-cost production of the tangible product of transport [6,7]; d) intangible and technologically unjustified measures of the product of the transport are taken - ton-kilometers and passengerkilometers, which have no physical meaning; e) at the level of axioms and basic design schemes, technical and technological innovations in MT are denied.

Purpose of the article: presentation of the main provisions of the conception and criterion apparatus for conceptual-innovative and energy -resource management on motor transport. Wherein the requirements of ensuring a system approach and the formation of a common strategic management methodology are taken into account, which includes models of important target functions of current management as particular cases.

\section{Main part}

The methods of conceptual innovation and energy resource management on MT must provide technological innovation of the Transport processes (TP), as well as the functions of the MT subsystem and of the MTS. Formed the following multiple model structure of MTS:

\section{$\mathrm{M}(M T S) \in(M T, T I, R N I, T S I, M H C, D S T R M$,}

$$
\text { SSTSM,PS, GITDS, SFS, SF, STC, SSF) }
$$

where: $M T$ - is the active subsystem "Motor transport"; $T I, R N I, T S I$ - terminal, road network and technical service infrastructures (infrastructure subsystems); MIIC - mechanisms of internal interface connections; DSTRM - demand segments of the transport resources markets (automobiles, fuel, drivers and workers); SSTSM supply segments of transport services markets; $P S$ - is the purpose of the system; GITDS - the goal of innovation and technological development of the system; $S F S$ - the subject of the functioning of the system; $S F$ many system functions; $S T C$ - system technology complex; $S S F$ - sets of subsystem functions (in subsystems $M T, T I, R N I, T S I)$.

The purpose PS of the MTS operation is individual (in the MT and TI subsystems) and mass (in the RNI and TI subsystems) transport integration of the discontinuous geometric space of the economic-social macrosystem (ESMS) in accordance with the transport demand, and also taking into account the operational and production requirements (adaptive performance, trajectory safety, transport energy efficiency) and terminal service requirements (timeliness of delivery, safety of goods and passengers, low cost) for motor transport processes [1]. The goal of managing the innovation and technological development of MTS (GITDS) is the long-term implementation of the concept of resource-synergistic transport integration of the macrosystem in a given transport and infrastructure space. Taking into account [8], a set of MTS system functions is formed: SF1 provision of subsystem resources for given traffic trajectories; SF2 - transport-interface compositions of subsystem resources; SF3 - transport emergence (mass transport-technological processes) and traffic regulation; SF4 - transport integration; SF5 neutralize dysfunctions; SF6-conceptual modernization of subsystems and system functions; SF7-modernization equifinality (resource synergistic integration of a given macrosystem space and innovative improvement of the energy- resource quality of the transport services (ERQTS).

The system technology complex (STC) consists of the following technologies: TT - transport, TMT terminal; TIT - transport - information; TMT - terminal; TMIT - terminal-informational; RCT - road construction; RMT - road maintenance; TFIT - traffic information; TST - technical - service. These technologies are included in the structures of the 
respective subsystems and together provide the implementation of two system functions SF2 and SF3.

At the same time, the theory of TT and the properties of its material and production components - TTC 2 are of decisive importance when solving problems of strategic management [4]. In addition, the implementation of high TT (technically progressive, energy efficient and resource saving) will ensure resource synergistic improvement of a variety of MTS system functions SF and functions of the MT subsystem. The MT subsystem "Motor transport" is designed to meet the transport demand of macrosystem entities based on high-quality production and technologically innovative reproduction of transportation services using tactical (servicecommercial) and strategic (conceptual-innovative and energy - resource) management methods.

The purpose of managing the innovative development of the MT subsystem is to increase the energy resource quality of of Transport services (ERQTS) taking into account the limitations of the TI and RNI subsystems based on maximizing the value of the objective function of technologically innovative projects and intensively resource-saving reproduction of Transportation services (TIIRSRTS) taking into account car markets. The functional structure of MT subsystem $\mathrm{S}_{\mathrm{MT}}$ is as follows:

$$
S_{M T} \in(M S, R T B, T T P)
$$

where $M S$ - is the $M T$ management superstructure (includes owners of capital, two types of $R_{T M}$ management resources for providing: commercial tactics of $M T-R_{T M 1}$ and strategic management of $\mathrm{R}_{\mathrm{TM} 2}$ ); RTB resource and technological base of $M T$; TTP - transport technological processes on MT.

As a functioning mode of transport, the MTS subsystem provides six of its functions (FMT): 1) FMT1 - transport production, in which the technological resources of MT $-R_{T L}$ are involved and energetically transformed into a physical product $\mathrm{W}_{\mathrm{p}}$, the FMT1 function is based on transport technologies and humanmachine labor and at the same time formed the emergent function MTS-SF3; 2) FMT2 - transport service, which is recorded on the basis of monitoring pairs of terminal events (sending - arrival of the joint venture); 3) FMT3 transport capital turnover as a scheme of cyclical movement of working and advanced capital; 4) FMT4 market supply of a technological resources of FMT1; 5) FMT5 - long-term and innovative-technological reproduction of transportation services on the principle of ensuring the technical and technological competitiveness of future transport supply; 6) FMT6 car maintenance and repair (additional and non-essential function for most motor transport enterprises). The subject of functioning of the MT subsystem is the implementation of the first five functions of FMT1 .... FMT5 based on the chain of life cycle of transportation services (LCTS) projects and projects of conceptual and innovative improvement of transport technologies (TT), components of MT: RTB and TTP.

The transport technology (TT) is understood as a set of scientifically-described methods (man-machine and energy- resources) of high-quality production of an MT product. The structure of the $\mathrm{S}_{\mathrm{TT}}$ transport technology is as follows [9]:

$$
S_{T T} C(T T C 1, T T C 2, T T C 3.1, T T C 3.2, T T C 3.3)
$$

where TTC1 - organizational forms of transport service on the basis of commercial projects of automobile delivery of goods or passengers; TTC2 - resourcetechnical and production-process component of the TT; TTC3.1 and TTC3.2 - the gnoseological and mathematical support of the components of TT - TTC1 and TTC2); TTC3.3 - rules and instructions for transport and terminal operations.

The structure of TTC2 includes the following elements:

$$
\text { TTC2 } C\left(M p, R_{T}, R_{E}, R_{L}, P_{R T}, P_{L}, P_{M}, E T, E T R P\right)
$$

where $M p$ - party masses of cargo or passengers; $\mathrm{R}_{\mathrm{T}}, R_{E}$, $R_{L}$ - carriers of technical (automobiles), energy (fuel) and labor resources (drivers) of MT, when they are connected in the structure of the car, the carrier of technological resources - $\mathrm{R}_{\mathrm{TL}}$ of the MT subsystem is formed; $P_{R T}-$ a set of properties of a car as a carrier of technical transport resources (as: a complex transport vehicle - $\mathrm{P}_{\mathrm{RT1}}$; a dangerous object of traffic control $\mathrm{P}_{\mathrm{RT} 2} ;$ a transportation means - $\mathrm{P}_{\mathrm{RT} 3}$, potential maintenance facility - $\mathrm{P}_{\mathrm{RT} 4}$; instruments of machine influences on the environment of motion - $\mathrm{P}_{\mathrm{RT} 5}$; constructive and technical basis of the process of transforming transport resources - $\mathrm{P}_{\mathrm{RT} 6}$; the element of the standard range of the rolling stock - $\mathrm{P}_{\mathrm{RT} 7}$; MT technological capital and a source of transportation profit - $\mathrm{P}_{\mathrm{RT} 9} ; P_{L}-$ many TT labor procedures; $P_{M}-\mathrm{a}$ set of machine procedures TT; $E T$ - the process of vehicle energy conversion; ETRP - is the process of energy transformation of transport technological resources into a physical product MT - Wp (phenomenological basis of transport production).

Many machine procedures PM consists of the following elements:

$$
P_{M} C\left(P_{M 1}, P_{M 2}, P_{M 3}, P_{M 4}, P_{M 5}, P_{M 6}, P_{M 7}\right)
$$

where is $P_{M 1} \ldots P_{M 7}$ - TT machine procedures: energy conversion - $P_{M 1}$; transmission - $P_{M 2}$; traction coupling $P_{M 3}$; trajectory-kinetic - $P_{M 4}$; trajectory orientational $P_{M 5}$; trajectory-transgressive - $P_{M 6}$ (ensuring safe free space on the road in front of a moving car); aerationtoxication - $P_{M 7}$.

Innovative development of TT is provided on the basis of design identification and substantiation of the complex of technical and technological innovations of NVTT:

$$
\text { NVTT E (NVKT, NVGT, NVTS, NVTL, NVET) }
$$

where $N V K T$ - are design and technical innovations in the structural-parametric organization Kjr of a new car; $N V G T$ - new vehicle parameters as a scientific and technical product; NVTS - innovations of transport service and TTC1; NVTL - technological innovations in the structure of TTC2; NVET - economic and 
technological innovations (resource-saving economy and TT).

The evolutionary model of the modular structuralparametric organization of the construction - Kjr of a new car (SPOCNC) for the analysis of NVKT and NVGT has the following form:

$$
K_{f r}^{N} \in\left(x_{t m p}^{N}, y_{t m l}^{N}\right)_{t r}
$$

where $x_{i m p}^{N}$ - is the updated subset of the p-th parameters of the $\mathrm{m}$-th constructive-functional module in the $\mathrm{i}$-th SPOCC device; $N-$ is the upper index of innovation; $y_{i m l}^{N}$ structure of the $\mathrm{m}$-th structural and functional module and the $i$-th device SPOCC, $(i=1,2 \ldots 4),(m=1,2 \ldots$ $4),(1=11,12,13 \ldots) ; j-$ is the class index of the rolling stock $\left(\mathrm{j}=1, \mathrm{n}_{\mathrm{c}}\right)$, where $\mathrm{n}_{\mathrm{c}}-$ is the number of vehicle classes); $r$ - is the index of the type of car in the $\mathrm{j}$-th class $\left(\mathrm{r}=1, \mathrm{n}_{\mathrm{v}}\right)$, where $\mathrm{n}_{\mathrm{v}}-$ is the number of variants of cars with the implemented technical innovations).

The subject of the MTS operation (SOMTS) is: subsystem, compositional, interface, and path-trajectory support for implementing a variety of system functions (SF) for the complex conversion of technological resources $\mathrm{R}_{\mathrm{TL}}$ of the transport into its physical product $\mathrm{Wp}$ and potential resources $\mathrm{R}_{\mathrm{mp}}$ of the macrocystem ESMS transform into real resources $R_{m r}$ according to logic scheme SOMTS:

$$
\text { SOMTSE }\left[(S F+\text { real }) \text { for: }\left(R_{T L}\left(\theta_{m}\right)+W_{p}\left(\theta_{m}\right)\right)+\left(R_{m p}+R_{m}\left(\theta_{T M}\right)\right)\right]
$$

where $W_{p}$ - is the physical product of transport [4]; $\theta_{r n}$ and $\theta_{m s}$ - road network and terminal trajectories of movement of carriers of technological resources $R_{T L}$ of transport; $\rightarrow$ - operator of change of a condition of the carrier of resources.

The carriers of potential resources - $R_{m p}$ of ESMS macrosystem are cargos $\left(R_{m p 1}\right)$ and passengers $\left(R_{m p 2}\right)$ before the transportation process begins. After the completion of this process, ESMS subjects, as consumers of transportation services, receive useful real resources $R_{m p 1}$ and $R_{m p 2}$. Transport need of macrosystem is expressed in the necessity for transport transformation of potential consumer resources $\mathrm{R}_{\mathrm{mp}}$ into real resources $\mathrm{R}_{\mathrm{mr}}$ in accordance with (8).

The macrosystem result of the transformations (8) is the transport integration of discontinuous geometric spaces of ESMS. At the same time, in transport operations, not only technological resources of transport are used, but also the material resources of two MTS infrastructures: terminal - $\mathrm{R}_{\mathrm{TI}}$ and road - $\mathrm{R}_{\mathrm{RI}}$. According to the material and production paradigm of MT (motor transport), its physical product $\mathrm{Wp}$ (this is the route set of impulses of the amount of movement of the vehicle's operating mass) is based on the controlled processes of the ETRP-energy transformation of technological resources $\left(\mathrm{R}_{\mathrm{TL}} \rightarrow \mathrm{Wp}\right)$ in adaptive transport operations. This takes into account three operational and production requirements: adaptive performance, trajectory safety and transport energy efficiency. In the production processes of a product in transport operations material production losses of technological transport resources $\Delta \mathrm{R}_{\mathrm{TL}}$ are formed, the value of which is determined by the amount of physical product $\mathrm{W}_{\mathrm{p}}$. However, in the theory of commercial management, only the accounting product of transport $\mathrm{W}_{\mathrm{a}}$ is analyzed, as a part $(40 \ldots$ $65 \%$ ) from physical product $\mathrm{W}_{\mathrm{p}}$. It is known that an accounting product $\mathrm{W}_{\mathrm{a}}$ is determined on the basis of a model of a virtual transport operation in which it is assumed that an "independent" movement of the net mass of cargo or passengers without taking into account the loss of technological resources $\Delta \mathrm{R}_{\mathrm{TL}}[6,7]$. In addition, the state of the road infrastructure resources RRI [9] has a significant impact on the production losses of the technological resources of the $\Delta \mathrm{R}_{\mathrm{TL}}$.

In transport processes and in the system (MTS), two types of complex mechanisms of interaction and compositions are formed: a) technological resources of transport $\mathrm{R}_{\mathrm{TL}}$ - with resources of road $\mathrm{R}_{\mathrm{RI}}$ and terminal $\mathrm{R}_{\mathrm{TI}}$ of MTS infrastructures; b) productive FMT1 and reproductive FMT5 transport functions - with SF system functions. Based on the technologically composite connection of these mechanisms, an integral structural functional organization of the system (SFO MTS) is formed, which allows you to realize the purpose of MTS - transport integrate ESMS macrosystem, which is an existential condition for the functioning of this macrosystem.

The purpose of the technologically innovative improvement of the energy- resource quality of the transportation services (ERQTS) is a comprehensive reduction of energy costs and transport resources in the production and reproduction of this transportation services. It follows that the presence of a compositional relationship between the two transport functions (FMT1 and FMT2) and the many functions of the SF system allows the concept of resource synergy in SFO MTS based on the objective ERQTS control function in the life cycle of the transportation services. Based on the above, logical-procedural schemes of structural and functional organizations of the SFO MTS system and transport SFO MT are formed:

$$
\begin{gathered}
{\left[S F 1\left(R_{T L}, R_{T I}, R_{R I}\right) \rightarrow S F 2(T T, S T C) \rightarrow\right.} \\
\text { FMT1 }\left(T T, S F 2, W_{p}\right) \rightarrow S F 3(T T, \text { FMT1 }) \rightarrow \\
S F 4\left(T T, \text { FMT1, } \theta_{r n}, \theta_{m M}\right) \rightarrow(S F 5 \rightarrow \text { real }) \rightarrow \\
S F 6\left(T T, S T C, F M T 5, E R Q_{T S}\right) \rightarrow \\
\left.S F 7\left(T T_{H}, S T C_{M}, S F 3_{R S}, S F 4_{R S}, S F 6_{R S}\right)\right] \rightarrow \text { FESMS }
\end{gathered}
$$

$$
\begin{gathered}
{\left[\mathbf{F M T 1}\left(T T, S F 2, W_{p}\right) \rightarrow \mathbf{F M T 2}\left(W_{p}\right) \rightarrow\right.} \\
\left.\mathbf{F M T 3}\left(W_{p}, T P R\right)\right) \rightarrow \mathbf{F M T 4}\left(R_{T L}, T T\right) \rightarrow \\
\left.\mathbf{F M T 5}\left(E R Q T S, T T_{i n}\right)\right]
\end{gathered}
$$

where FMT1 and FMT5 - are the functions of production and reproduction of the transportation services in transport; ERQTS - energy-resource quality of the transportation services; $T P R$ - three production requirements for transport operations; $T T_{\text {in }}$ - innovative TT; $S T C_{M}$ - the complex of the modernized technologies of the MTS system; $S F_{R S}$ - system functions that correspond to the concept of resource synergy in the 
MTS system; FESMS - functioning economic - socium system.

Based on the SFO MTS (9) and SFO MT (10) schemes, a systematic methodology of strategic management on MT has been developed, taking into account the following requirements [10]:

- structuring of MT and MTS functions, and components of transport technologies;

- the essential and technological analysis of transport production taking into account the properties of technical resources and dysfunctions of the road infrastructure (trajectory conflicts and transport pro-anergic phenomenon);

- structural and parametric analysis of vehicles with structural and technical innovations;

- physical, technical and technological causality of road transport operations, as well as the processes of transformation of the technological resources of transport and potential resources of the macrosystem;

- test and standard - comparative analysis of the transport energy efficiency of cars;

- a gradual increase in the values of indexes of energytechnological and energy-resource efficiency of the transport processes, taking into account road and operating conditions of transport operations;

- justification of a set of technical and technological innovations in transportation service life cycle projects;

- ensuring energy and technologically innovative resource-synergies in Motor transport system (MTS) based on the cumulative effect of transport and infrastructure resource saving;

- provision of innovative-technological and resourceintensive reproduction of transportation services based on innovative models of intensive surplus product of transport and future transport profits.

In accordance with these requirements and with the concept of resource-synergistic improvement of transport functions and the transport system, a conceptual-criterial apparatus has been developed for techno-innovative and systemic management of the energy- resource quality of transportation services. It is designed to solve innovative problems of strategic management in motor transport using a set of mathematical models and methods. Some methods are presented below:

- the theory of operational kinematics and energy by adaptive-discrete movement of the car as a carrier of technical resources of transport (with variable structural and parametric organization of the structure);

- calculation schemes and models of transport and technological operations, taking into account the processes of energy transformation of technological resources into a physical product of transport;

- testing and standard-comparative method of simulative analysis of the transport energy efficiency of vehicles with variable parameters for different projects of the life cycle of transportation services;

- the method of simulative analysis of energy technology efficiency of transport operations for different types of the road transportations, taking into account the changes in structural, technical, road and operational factors;
- the method of simulative analysis of technical and technological innovations of NVTT and the standard comparative formation of projects for innovative and intensive resource-saving reproduction of transportation services.

The following are mathematical models for a simulative and standard-comparative analysis of some indexes of energy efficiency of automobiles and technological projects of transportation, as well as energy- resource quality of transportation services:

a) the dimensionless indexes of the transport energy efficiency of an automobile $\mathrm{P}_{\mathrm{E}}\left(\mathrm{K}_{\mathrm{jr}}\right)$ with a given variant of the characteristics of its structural-parametric organization $\mathrm{K}_{\mathrm{jr}}$ is determined as follows:

$$
\begin{gathered}
P_{\mathrm{E}}\left(K_{f r}\right)=\frac{K_{V R}\left(K_{f r}, \mathrm{P} R 1, \mathrm{P} 2\right)}{K_{\mathrm{EP}}\left(K_{l}, \mathrm{P} 21, \mathrm{P} R 2\right)} \cdot \frac{\gamma_{s}}{\left(\gamma_{s}+\eta_{s}\right)} \rightarrow \max \\
K_{f r} \rightarrow \operatorname{Var}, P_{R 1} \rightarrow \text { Var }, P_{R 2} \rightarrow \text { Var }
\end{gathered}
$$

where $K_{V P}$ and $K_{E P}$ - are the energy coefficients of the vehicle speed and its mileage for the calculated test route (determined by the method of mathematical modeling of the processes of energy conversion of technological resources of transport $\mathrm{R}_{\mathrm{TL}}$ into physical product $\mathrm{W}_{\mathrm{p}}$ ); $P_{R I}$ and $P_{R 2}$ - properties of the road as rolling surface and as a communicative channel; $\gamma_{s}$ and $\eta_{e}-$ are the load capacity utilization factors (or bus capacity) of the vehicle and of its equipped weight.

An example of the results of the parametric analysis of the influence of the maximum power $\mathrm{Nm}(\mathrm{kW})$ of the engine of a VOLVO FH-12 FRUEHAUF DSND-32 auto train on a set of indicators of its energy efficiency in the test operation is shown in Figure 1.

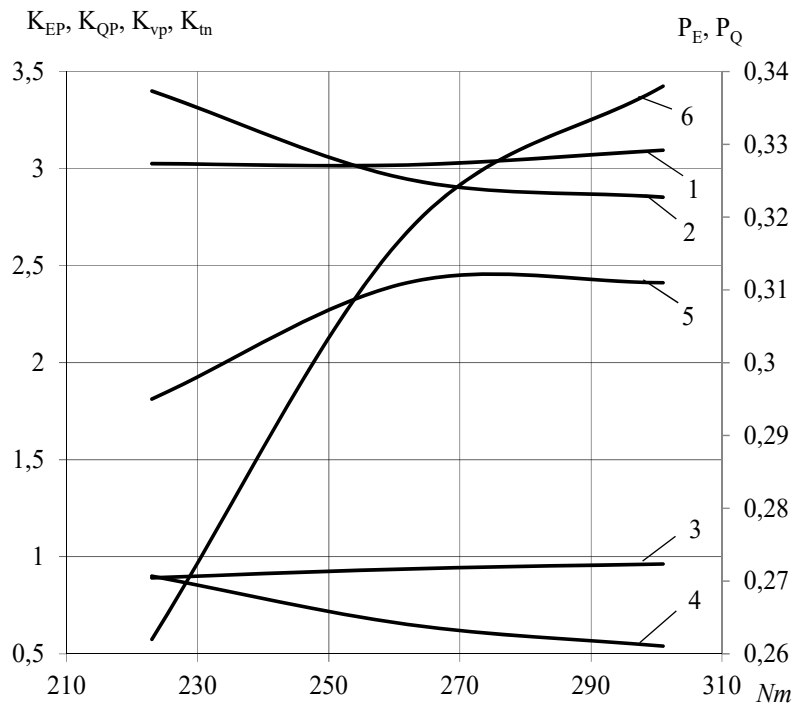

Fig. 1. Graphs of the dependence of the energy efficiency indicators of the VOLVO FH-12 + FRUEHAUF DSND-32 highway train on the maximum engine power $\mathrm{Nm}(\mathrm{kW})$ for the calculated test route:

$1-\mathrm{K}_{\mathrm{EP}}, 2-\mathrm{K}_{\mathrm{QP}}, 3-\mathrm{K}_{\mathrm{vp}}, 4-\mathrm{K}_{\mathrm{tn}}, 5-\mathrm{P}_{\mathrm{E}}, 6-\mathrm{P}_{\mathrm{Q}}$.

The following designations are taken in the figure: $1-\mathrm{K}_{\mathrm{EP}^{-}}$ coefficient of energy mileage; $2--\mathrm{K}_{\mathrm{QP}}$ - coefficient of fuel consumption; 3- $\mathrm{K}_{\mathrm{vp}}$ - average velocity coefficient; $4-\mathrm{K}_{\mathrm{tn}}{ }^{-}$ indicator of the share of unsteady modes of movement of the road train in the test operation; $5-\mathrm{P}_{\mathrm{E}}$ - indicator of transport energy efficiency; 6 - $\mathrm{P}_{\mathrm{Q}}$ - indicator of fuel efficiency. 
Such test characteristics were obtained for modifications of different types of cars (small, medium and heavy load capacity, road trains and buses). Based on the test and multicriteria analysis of possible modifications of car types, two groups of conditions for their conceptual and innovative justification are determined taking into account their resource-technical properties of $\mathrm{P}_{\mathrm{RT}}$ and machine procedures of $\mathrm{P}_{\mathrm{M}}$ transport technologies according to expression (4): a) conditions for increasing transport energy efficiency and compliance with energy-saving transport technologies, which are achieved by maximizing the values of four criteria $\left(\mathrm{K}_{\mathrm{vp}}, \mathrm{P}_{\mathrm{E}}, \mathrm{P}_{\mathrm{Q}}, \mathrm{TE}\right) \rightarrow \max$, where $\mathrm{TE}-$ is the indicator of the transport return of machine procedures PM transport technologies; b) the condition for an indirect assessment of the toxicity of a vehicle in a transport operation based on the requirement to minimize the values of two criteria $\left(K_{Q p}, K_{t n}\right) \rightarrow \min$.

b) The index of transport efficiency TE of machine procedures $\mathrm{P}_{\mathrm{M}}$ of transport technologies in test operations is determined as follows:

$$
\mathrm{TE}=\frac{M_{p} * V}{P_{\alpha} * t} \rightarrow \max
$$

where $M_{p}$-party mass of cargo or passengers; $V$ and $t-$ the speed and time of movement of the car in a given phase of the test operation; $P_{a}$ - average thrust force of the car in a given phase of the test operation;

c) criteria for improving the energy-technology efficiency of road transportation:

- energy coefficient of the technological performance of the vehicle as a carrier of technical resources of transport - Kw:

$$
\begin{aligned}
& K_{W}\left(K_{f r}, F_{Q}, N V T T, t\right) \rightarrow \max \\
& K_{f r} \rightarrow \operatorname{Var}, E_{Q} \rightarrow \text { Var }, t \rightarrow \operatorname{Var}
\end{aligned}
$$

where NVTT - is a set of technical and technological innovations in the life cycle of road transport services (constructive-technical, goods-technical, organizational, technological and economic-technological); $F_{o}$ - many operational factors of the transport cycle [6]; $t$ - variable time;

- energy coefficient of the cost of transportation taking into account the technologically innovative production of the Motor transport - Ks:

$$
\begin{gathered}
K_{s}\left(K_{f r}, F_{Q}, \text { Kep, Kvp, NVTT }, \frac{C_{f}}{C_{v}}, t\right) \rightarrow \min , \\
K_{f r} \rightarrow \text { Var }, E_{o} \rightarrow \text { Var }, t \rightarrow \text { Var }
\end{gathered}
$$

where $C_{f} / C v$ - the ratio of specific fixed and variable costs of the transportation in the estimated car ride; $K_{j r}-$ a set of characteristics of the structural and parametric organization of the design of a new car;

d) energy-equivalent criteria of the energy-resource efficiency of the road transportation and the quality of the transportation services - (ERQTS):

$$
\begin{aligned}
& K_{w}\left(K_{j r}, F_{Q}, N V T T, t\right) * W_{\mathrm{r} 0}\left(F_{Q}\right) \rightarrow \max \\
& K_{S}\left(K_{j r}, F_{Q}, N V T T, t\right)=S_{w 0}\left(F_{Q}\right) \rightarrow \min
\end{aligned}
$$

where $W_{r 0}$ and $S_{w 0}$ - are the indexes of the transportation productivity and transportation cost price) for the current time $t_{0}$, which are determined according to the scheme of the transposition process [6];

e) the dimensionless objective function $\mathrm{COF}_{\mathrm{RS}}$ of the system-conceptual management of innovative functional resource- synergy projects at Motor transport (MT) and MTS - system is formed taking into account (9) .... (15) and has the following form:

$$
\begin{gathered}
\operatorname{COF}_{R S}=\frac{P T h(N V T T, t)}{W_{\text {ro }} * T_{W o}}=\left(1+\beta_{R}(N V T T, t)\right) \\
{\left[\frac{m_{\mathrm{T}}(t)}{m_{\alpha}(N V T T, t)}-m_{S}(N V T T, t) \approx F_{T S}\right] \rightarrow \max }
\end{gathered}
$$

where $P T h$ - is the hourly transport profit; $\beta_{R}-$ the index of the innovative increase in the energy-resource efficiency of the technological transportation project, with $\beta_{\mathrm{R}}>0$ the effect of the obtaining a technologically intensive surplus product of transport is provided, which is a necessary condition of transport resource synergy in technological projects; $m_{T}(t)$ - is the coefficient of the forecast growth of the tariff $\mathrm{T}_{\mathrm{w} 0}$ per $1(\mathrm{t} * \mathrm{~km}), \mathrm{m}_{\mathrm{T}}(\mathrm{t})>1$; $m_{a}$ - is the index of the modernization reduction of the value of coefficient of the transport pro-anergic disfunction of the road $-\mathrm{K}_{\mathrm{tpd}}$ on a given transportation route, $\mathrm{m}_{\mathrm{a}}=\mathrm{K}_{\mathrm{tpd}}(\mathrm{t}) / \mathrm{K}_{\mathrm{tpd}}\left(\mathrm{t}_{0}\right) \mathrm{m}_{\mathrm{a}}<1 ; m_{s}-$ is an index of innovative reduction in the value of the energy coefficient $\mathrm{K}_{\mathrm{s}}$ of the cost of transportation; $\mathrm{m}_{\mathrm{s}} \leq 1 ; F_{T S}-$ is the economic factor of the current organization of transportation services (the ratio of the cost of transportation and tariff $\mathrm{T}_{\mathrm{w} 0}$ for transportation) $F_{T S}=0.55 \ldots 0.8$.

Model (16) with the system-conceptual management of innovative projects of functional resource synergy at MT and MTS provides the solution of three new development tasks: a) improving the energy- resource quality of the transportation services - ERQTS; b) the formation of projects of technologically innovative and resource-saving reproduction transportation services of TIRSRTS; c) analysis of the compliance of the modernization projects of the elements of the road and terminal infrastructures of the MTS with the resourcesynergistic development concept.

The objective function $\mathrm{COF}_{\mathrm{sm}}(\mathrm{i})$ of strategic management at motor transport for the i-th development project (model of future profit in technologically innovative projects of transport processes) has the following form:

$$
\begin{gathered}
C O F_{s m(i)}(t)=\left(C O F_{R S(i)}(N V T T, t) \cdot W_{20(i)} \cdot T_{w 0(i)}\right) \rightarrow \max , \\
i \in\left(1, N_{p r}\right), C O F_{R S(i)}(t)>0
\end{gathered}
$$

where $\mathrm{Npr}-$ is the number of versions for technologically innovative strategic management projects at motor transport. 


\section{Conclusions}

1. Established the principal (from the point of view of ensuring the innovative development of transport technologies and processes) shortcomings of the existing theory of transport analysis and management; they are due to the previously adopted simplified paradigm of knowledge about transport as a sphere of commercial transport services, as well as the axiom of the immutability of the parameters of automobiles and transport technologies. Due to these shortcomings, these theories do not correspond to the goals of strategic management.

2. Technologically innovative concept of resourcesynergistic transport integration of the country's economic and social macrosystem and a methodology for its implementation have been formed.

3. Established the structures and functions of both the transport system and the subsystem "Motor transport"; The ways of innovative resource saving on motor transport and in infrastructure subsystems are revealed.

4. A set of methods is proposed for the technologically innovative management of the energy resource quality of transport services and for resource-synergistic improvement of the functions of the transport system with its subsystems.

5. An analytical model of the objective function of strategic management in motor transport is proposed, which provides the concept of resource-synergistic transport integration of the economic and social macrosystem.

6. On the basis of this system methodology, it is recommended that: a) in motor transport implement technological and innovative strategies for the staged improvement of the energy resource quality of motor transportation services; b) in the road infrastructure -to ensure the minimization of the indicators of trajectory conflicts and transport pro-anergic disfunctions of road sections; c) in the terminal infrastructure - minimize logistical costs.

\section{References}

1. R. Khabutdinov, A. Khabutdinov, Visnyk NTU, 17, 134 (2008)

2. A. Gadjinsky, Logistics (2008)

3. O. Petrashevskiy, A. Khabutdinov, Transport problems, 6, 60 (2009)

4. R. Khabutdinov, O. Kоtsyк, Energy-resourse efficiency of the car (1997)

5. K. Macconel, S. Brue, Economics: Principles, problems and politics (1992)

6. A. Vorkut, Motor transportations of goods (1986)

7. M. Khodosh, B. Daskovsky, Organization, economics and management of cargo transportation by motor transport (1989)

8. M. Setrov, General principles of organization of systems and their methodological significance (1971)

9. R. Khabutdinov, Transport problems, 3, 164 (2006)

10. R. Khabutdinov, Visnyk NTU, 24, 237 (2011)

11. G. Prokudin, O. Chupaylenko, O. Dudnik, A. Omarov, Eastern-European Journal of Enterprise Technologies Vol. 6, Issue 3 (84). P. 54-61 (2016). doi: $10.15587 / 1729-4061.2016 .85211$ 